\title{
Experimental Study of Structural Performance of Precast Concrete Insulated Sandwich Panels with Cruciform Cross Section GFRP Connectors
}

\author{
Xiaohong Yang ${ }^{1}$, Yu Jiang ${ }^{1, a}$, Huyue Sun ${ }^{1}$ and Zhenghua Sun ${ }^{1}$ \\ ${ }^{1}$ Jiangsu Research Institute of Building Science Co., Ltd., 210008 Nanjing, China
}

\begin{abstract}
This study investigated the structural performance of precast concrete insulated sandwich panels with cruciform cross section glass fiber-reinforced polymer (GFRP) connectors, based on tensile and shear tests. 5 tensile specimens and 4 shear specimens were fabricated and tested. The load-displacement relation and failure mode of the specimens were analyzed. The results revealed that the average ultimate tension load of the tested specimens with single GFRP connector was $13.14 \mathrm{kN}$ with concrete splitting or concrete partial cone failure. For the shear specimens, the average ultimate shear load was $14.83 \mathrm{kN}$ with rupture failure of GFRP connector. Furthermore, durability of sandwich panels was investigated, by fabricating and testing 48 tensile specimens with GFRP connectors immersed in $30^{\circ} \mathrm{C}$ and $60^{\circ} \mathrm{C}$ alkaline solution for $30 \mathrm{~d}, 60 \mathrm{~d}, 90 \mathrm{~d}, 120 \mathrm{~d}, 150 \mathrm{~d}$ and $180 \mathrm{~d}$. The results indicated that aging of GFRP connectors in alkaline environment would not reduce, but slightly increase the load capacity of the tensile specimens. In addition, safety evaluation of precast concrete sandwich panels was conducted based on the data of structural performance tests. The result showed that the sandwich panels with GFRP connector subjected to combined shear and tension load had sufficient safety in different design situations.
\end{abstract}

\section{Introduction}

Precast concrete insulated sandwich panels, consist of two concrete wythes and a layer of insulation in between, are widely used as load-bearing cladding in commercial and residential structures nowadays [1]. Connectors are crucial components in the concrete sandwich panels, which significantly influence the bearing capacity, stiffness and other properties of the panels [2]. Bent reinforcing bars, sleeve anchors and welded-wire truss were typical connectors used in sandwich panels [3]. However, the material of connectors was usually steel, which may potentially compromise the thermal insulation value of the sandwich panel or degrade due to corrosion [4].

The glass fiber-reinforced polymer (GFRP) connector is a new option in the recent decades, with the advantages including high tensile strength, less heat conduction and easy application. Studies had been conducted to evaluate the structural performance of GFRP connectors, including tensile, shear and flexural behavior of concrete sandwich panels with GFRP connectors [5-9]. Previous research indicated that concrete sandwich wall panels with GFRP connectors had satisfactory composite behavior.

This study investigated the structural performance of precast concrete insulated sandwich panels with recently developed cruciform cross section GFRP connectors, based on tensile and shear tests. Durability of concrete sandwich panels with GFRP connectors was evaluated in this research, by tensile test on sandwich specimens with aged GFRP connector exposed in simulated concrete pore solution before fabrication. In addition, safety evaluation of precast concrete insulated sandwich panels with cruciform cross section GFRP connectors was conducted based on the results from tensile and shear tests.

\section{Tensile test of precast concrete insulated sandwich panels with GFRP connectors}

\subsection{Experimental investigation}

Concrete used in this set of tests had an average $28 \mathrm{~d}$ strength of $43.1 \mathrm{Mpa}$ with standard deviation of 5.5Mpa. The concrete blocks were reinforced with $10 \mathrm{~mm}$ diameter bars. Yield strength and ultimate strength of the reinforcement was $400 \mathrm{MPa}$ and $540 \mathrm{MPa}$, respectively. The dimensions of the GFRP connectors were illustrated in Figure. 1, and the properties of the GFRP connectors were reported in Table 1.

\footnotetext{
${ }^{a} \overline{\text { Corresponding author: xavilt0603@foxmail.com }}$
} 

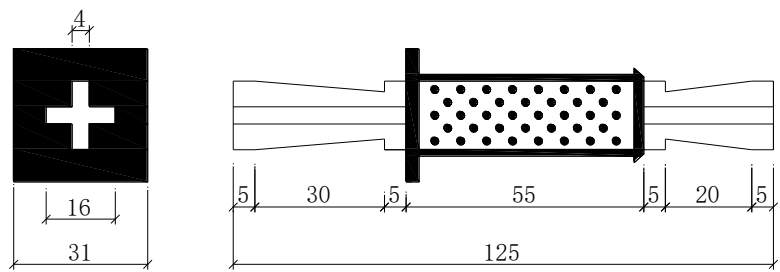

Figure 1. Dimensions of GFRP connectors (unit: mm).

Table 1. Properties of the GFRP connectors.

\begin{tabular}{|c|c|c|}
\hline $\begin{array}{c}\text { Tensile strength } \\
\text { (MPa) }\end{array}$ & $\begin{array}{c}\text { Shear strength } \\
\text { (MPa) }\end{array}$ & $\begin{array}{c}\text { Modulus of } \\
\text { elasticity (GPa) }\end{array}$ \\
\hline 895 & 62.5 & 48.4 \\
\hline
\end{tabular}

A total of five tensile specimens were cast and tested. The specimens were $200 \times 200 \times 430 \mathrm{~mm}$ sandwich systems, which consisted of two $190 \mathrm{~mm}$ thick concrete blocks with a $50 \mathrm{~mm}$ layer of extruded polystyrene (XPS) foam insulation between them. One single GFRP connector was placed perpendicular to the interface through the XPS insulation. $10 \mathrm{~mm}$ diameter reinforcing bar and $16 \mathrm{~mm}$ diameter pull rods were provided in the concrete blocks (Figure. 2). The pull rods and GFRP connectors were fixed at centroid line of the specimen to avoid eccentric force and torsion during the experiment.

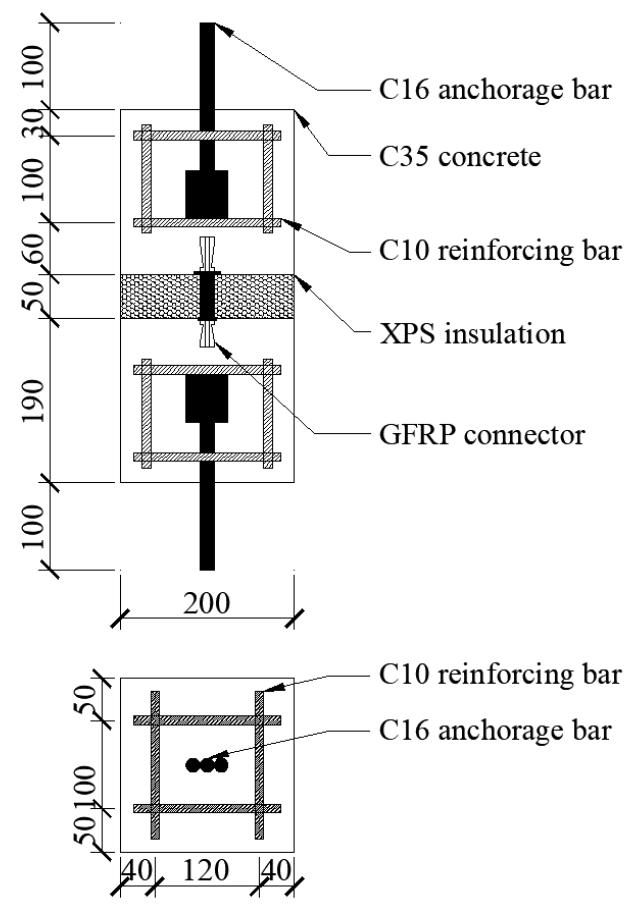

Figure 2. Tensile test specimen (unit: $\mathrm{mm}$ ).

The test setup of this experiment was illustrated in Figure 3. After 28d curing, tension force was applied on the specimens using a hydraulic actuator at a rate of $1 \mathrm{~mm}$ per minute. Two dial gauges were attached on each specimen to measure the displacement between two concrete blocks. Data were recorded using the SANS PowerTest data acquisition system.

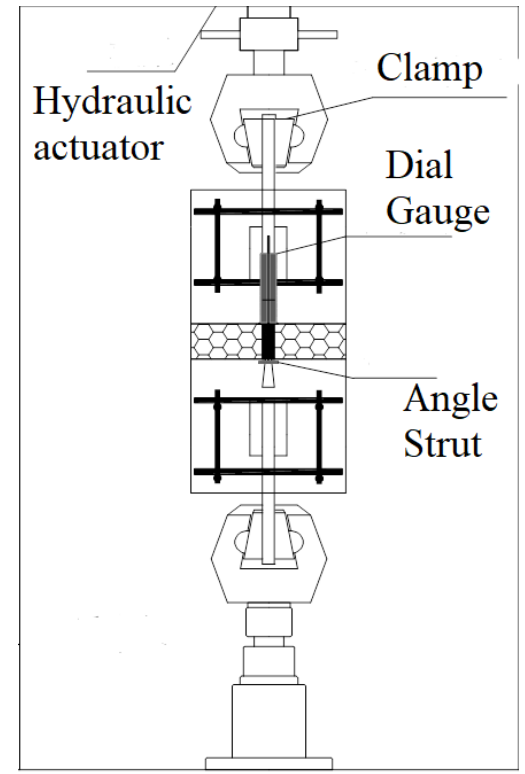

Figure 3. Tensile test setup.

\subsection{Results and discussion}

In this experiment, five duplicate tensile specimens (SJ-1 SJ-5) were loaded until failure of the specimens. Figure 4. presented the load versus displacement curves for all tensile specimens. According to the curves, load-displacement responses could be divided into three stages[10]. Stage 1 was before tension force loaded to $0.1 \sim 0.3 \mathrm{Fu}$, while the displacement was between 0 to $0.25 \mathrm{~mm}$. In stage 1 , the tensile specimens deformed elastically and, therefore load-deflection was approximately linear. No crack or damage were observed during this stage. Then, load was raised to $\mathrm{Fu}$ in stage 2, along with the increase of displacement to $3.0 \mathrm{~mm} \sim 5.0 \mathrm{~mm}$. In this stage, tensile specimens reached elastoplastic phase, and thus the load-deflection relation became non-linear, but the increment in deflections was still nearly proportional to the increasing load. Bond at the interface between concrete and XPS insulation started to lose, and crack generated on concrete at this stage. Concrete cone gradually formed around the GFRP connector, correspondingly. Afterwards, the specimens turned in to stage 3 , which was the unloading phase. The load-deflection curves dropped sharply, while the GFRP connectors were pulled out with concrete cone or concrete splitting, accordingly.

The average ultimate load $(\mathrm{Fu})$ of the specimens was $13.14 \mathrm{kN}$ (Table 2). Two typical types of failure were observed after testing, which were concrete $\mathrm{Y}$ shape splitting failure and partial cone failure, as shown in Figure 5[11,12]. Fu of SJ-3, which had concrete splitting failure, was larger than $\mathrm{Fu}$ of the other specimens with concrete partial cone failure. None of crack, fracture or other obvious damage was found on the GFRP connectors. Toutanji and Gomez also found the failure of concrete beams externally bonded with FRP composite sheets was not due to rupture of FRP, but rather due to the debonding 
between the FRP sheet and the concrete interface, correspondingly[13]. This phenomenon could be in accordance with the fact that the tensile strength of GFRP connectors was significantly greater than the pull-out strength and bonding strength of GFRP connectors. Thus, pull-out strength of GFRP in concrete could be the primary factor which influence the tensile strength of the sandwich specimens.

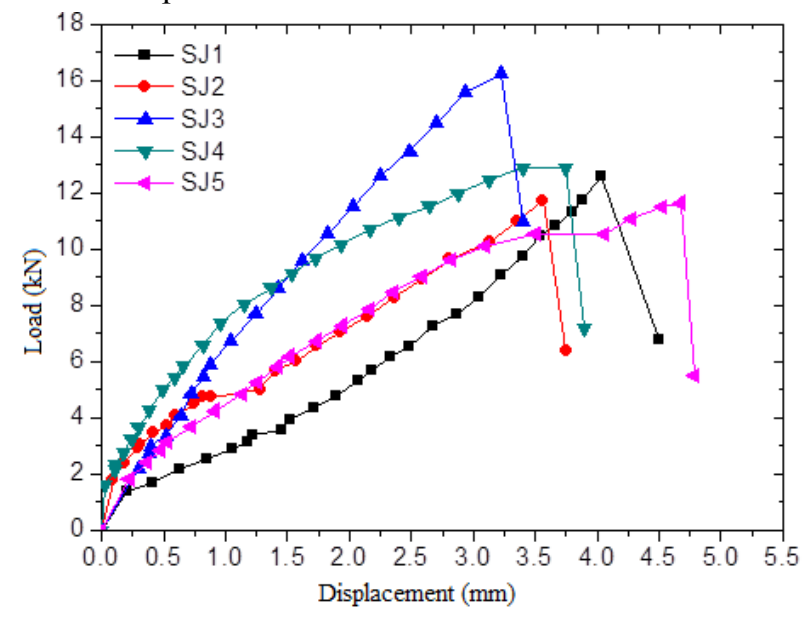

Figure 4. Load-displacement responses of tensile specimens.

Table 2. Results of tensile test.

\begin{tabular}{|l|l|l|l|l|l|}
\hline Specimen & SJ-1 & SJ-2 & SJ-3 & SJ-4 & SJ-5 \\
\hline Fu (kN) & 12.59 & 12.30 & 16.25 & 12.90 & 11.66 \\
\hline $\begin{array}{l}\text { Failure } \\
\text { type }\end{array}$ & $\begin{array}{l}\text { partial } \\
\text { cone }\end{array}$ & $\begin{array}{l}\text { partial } \\
\text { cone }\end{array}$ & splitting & $\begin{array}{l}\text { partial } \\
\text { cone }\end{array}$ & $\begin{array}{l}\text { partial } \\
\text { cone }\end{array}$ \\
\hline
\end{tabular}

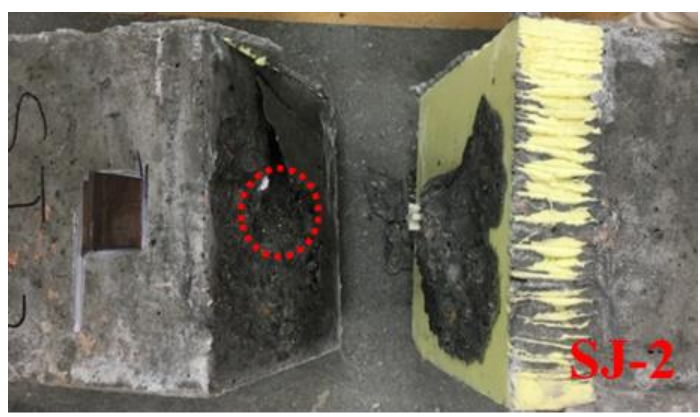

a. Concrete partial cone failure

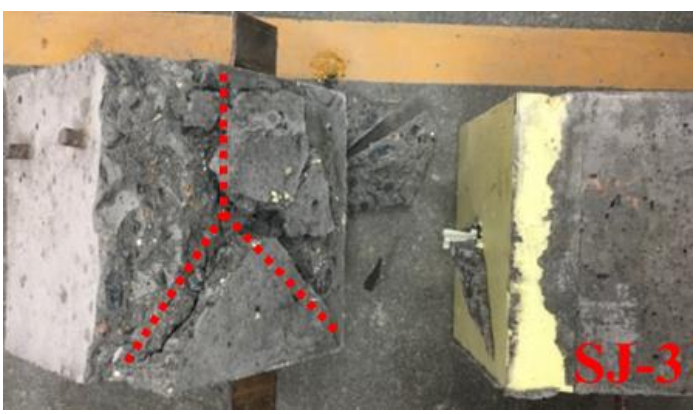

b. Concrete splitting failure

Figure 5. Typica failure type of tensile specimens.

\section{Shear test of precast concrete insulated sandwich panels with GFRP connectors}

\subsection{Experimental Investigation}

Four duplicate shear specimens (JQ1 JQ4) were made in this study, as presented in Figure 6. GFRP connectors, concrete and rebar used in the shear specimens were same with materials used in tensile specimens. Each specimen consisted of two concrete wythes with a $50 \mathrm{~mm}$ layer of XPS foam insulation between them. The dimensions of the two wythes were $900 \times 600 \times 60$ and $1400 \times 600 \times 180$, respectively. Square steel meshes of $10 \mathrm{~mm}$ diameter bas with $200 \times 200 \mathrm{~mm}$ openings was used as the longitudinal and transverse reinforcement of both wythes. Single layer of reinforcement was applied in the top wythe, while double layers were implemented in the bottom wythe. Two GFRP connectors were placed perpendicular to the wythe face through the insulation.
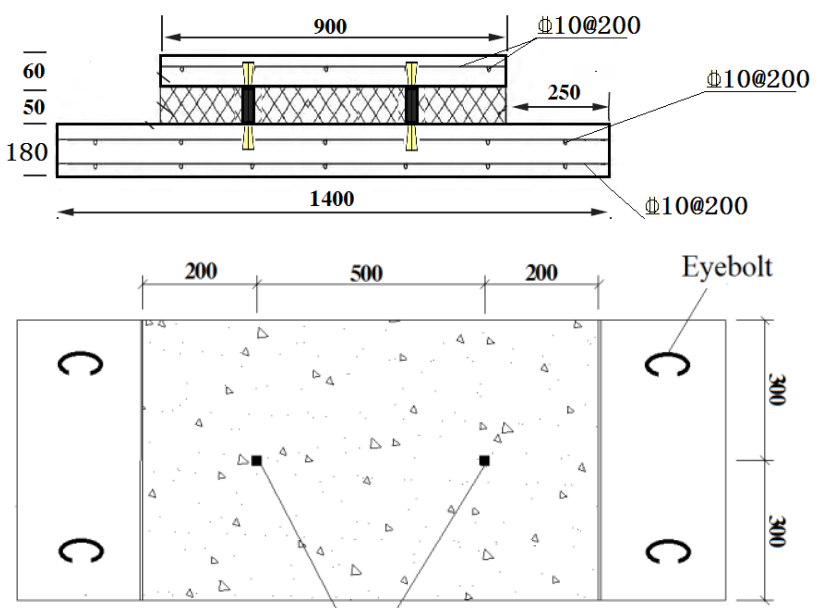

GFRP Connector

Figure 6. Shear test specimen (unit: $\mathrm{mm}$ ).

Shear tests were conducted after $28 \mathrm{~d}$ curing of the specimens. As illustrated in Figure 7. the bottom wythe was fixed using steel plates and foundation bolts. Hydraulic jack and steel beam with sufficient stiffness were used to apply horizontal uniform load on the top wythe. Three dial gauges were attached to the top wythe to test the displacement between top and bottom wythes. Multi-stages static loading was applied on the specimens. In the first stage, load was applied using force control at a rate of $1 \mathrm{kN}$ per level till peak load was reached. Then, load was applied using stroke control at a rate of $2 \mathrm{~mm}$ per level till failure of the specimens. 

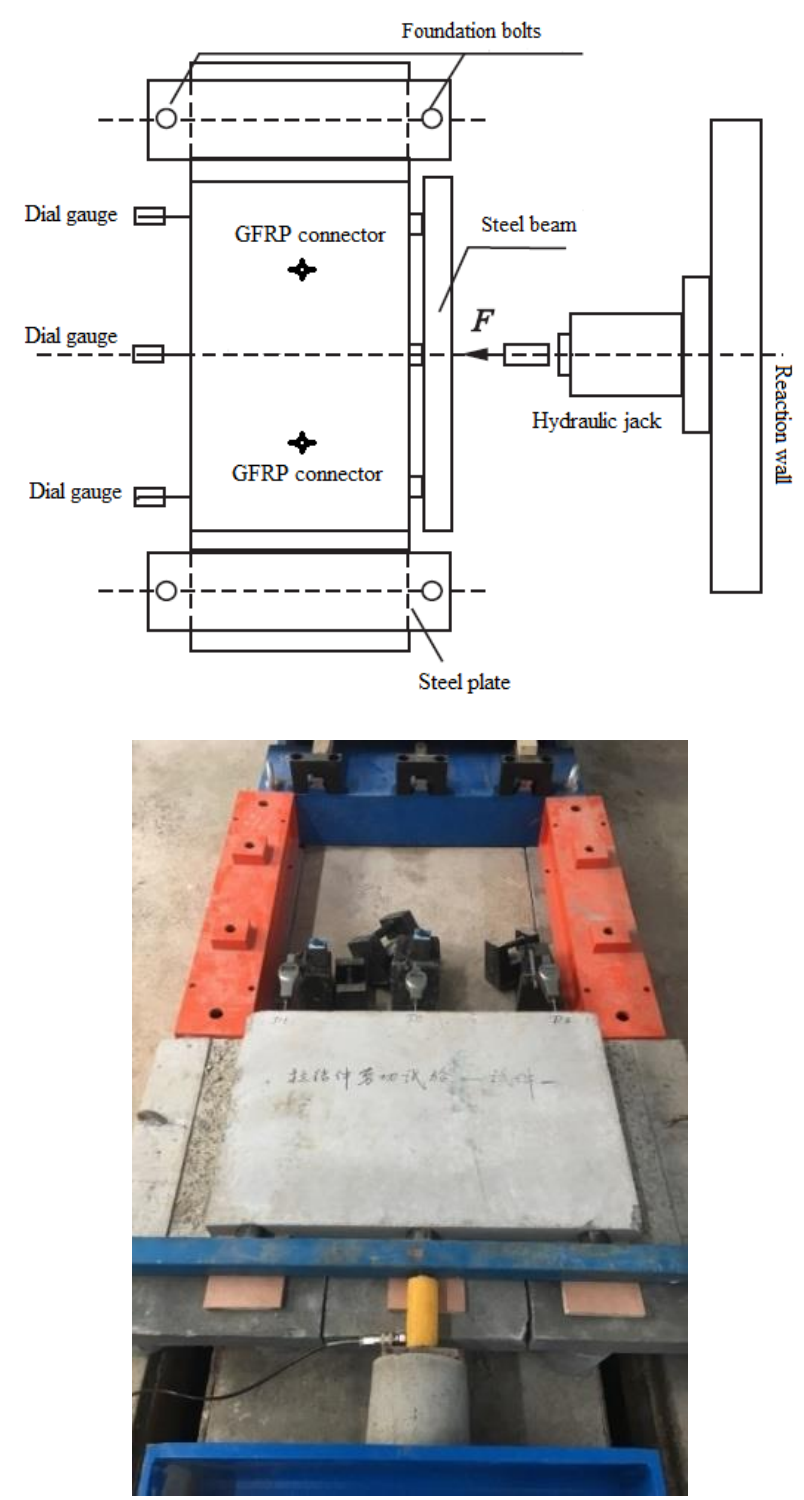

Figure 7. Shear test setup.

\subsection{Results and discussion}

Figure 9 illustrated the load-displacement curves for all shear specimens. Critical points to differentiate various stages were also marked on the profile. Before point A, shear specimens were in plastic stage, in which load-displacement had nearly linear relation. Load was between $0 \sim 4 \mathrm{kN}$ during this stage, in which no remarkable phenomena observed at the same time. From point A to point B, the load-displacement curve turned into parabolic profile. Fricative was typically heard at this stage, indicating failure of the adhesion bond between the concrete and the insulation. Thus, shear load was born almost by the GFRP connectors exclusively since then. From point $\mathrm{B}$ to point $\mathrm{C}$, displacement increased linearly with the raise of shear force, until ultimate load was reached. The average ultimate load of the shear specimens was $29.65 \mathrm{kN}$, while the average displacement between the concrete wythes was $18.44 \mathrm{~mm}$ (Table 3 ).
Hence, the ultimate shear capacity of single GFRP connector in this study was $14.83 \mathrm{kN}$. Non-negligible noise could be noticed, which may reflect the fracture of fibers in GFRP connectors. From point $C$ to point D, the load-deflection curve dropped sharply in the unloading stage by the end of loading. At the end of the test, it could be observed that all the specimens failed with rupture of GFRP connectors, as presented in Figure 8.

Table 3. Results of shear tests.

\begin{tabular}{|c|c|c|c|c|}
\hline $\begin{array}{c}\text { Specime } \\
\mathbf{n}\end{array}$ & $\begin{array}{c}\text { Ultimat } \\
\text { e load } \\
(\mathrm{kN})\end{array}$ & $\begin{array}{c}\text { Avg } \\
\text { ultimat } \\
\text { e load } \\
(k N)\end{array}$ & $\begin{array}{c}\text { Displacement } \\
(\mathbf{m m})\end{array}$ & $\begin{array}{c}\text { Avg } \\
\text { displace } \\
\text { ment } \\
(\mathrm{mm})\end{array}$ \\
\hline JQ1 & 28.2 & \multirow{4}{*}{29.65} & 17.56 & \multirow{4}{*}{18.44} \\
\hline JQ2 & 31.1 & & 21.47 & \\
\hline JQ3 & 31.2 & & 17.01 & \\
\hline JQ4 & 28.1 & & 17.72 & \\
\hline
\end{tabular}

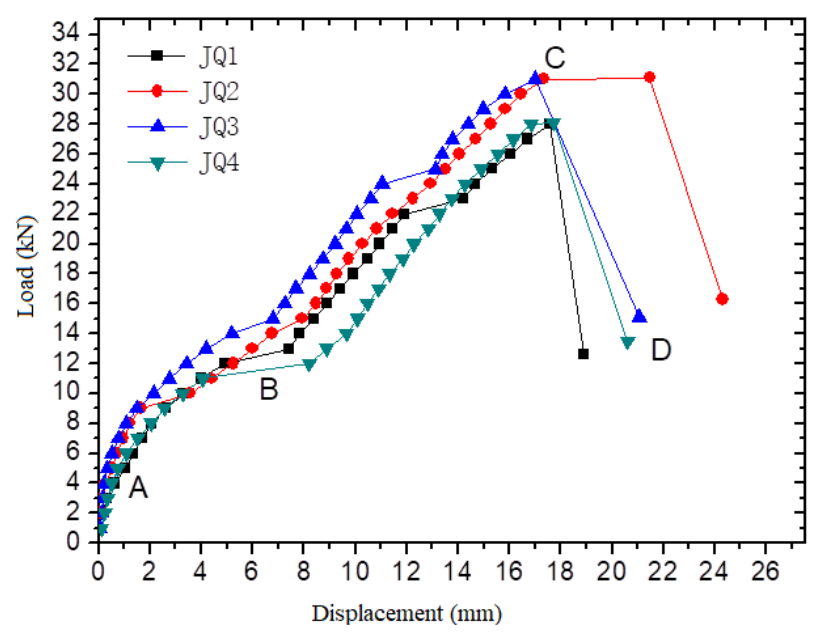

Figure 8. Load-displacement responses of shear specimens.

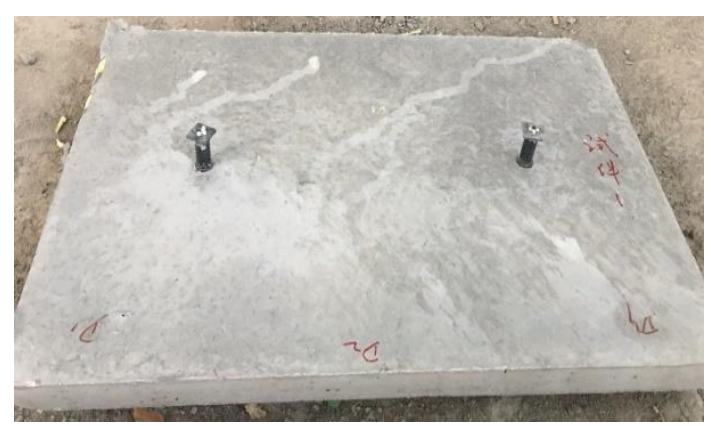

Figure 9. Failure of shear specimens. 


\section{Durability test of precast concrete insulated sandwich panels with GFRP connectors}

Accelerated aging of GFRP connectors in accordance with ACI440.3R-12 was conducted in the durability tests [14]. The materials and specimens used were same with the experimental setup of tensile tests in section 2, excluding the GFRP connectors. The GFPR connectors were immersed in the $25^{\circ} \mathrm{C}$ and $60^{\circ} \mathrm{C}$ alkaline solution for $30,60,90,120,150$ and 180 days, respectively. The composition of alkaline solution which could be a representative of the porewater inside Portland-cement was listed in Table 4. After exposure in alkaline solution, GFRP connectors were embedded in the specimens. Table 5 summarized the specimens fabricated in the durability tests.

Table 4. Composition of alkaline solution.

\begin{tabular}{|l|l|l|l|}
\hline $\mathbf{C a}(\mathbf{O H})_{2}$ & KOH & $\mathbf{N a O H}$ & $\mathbf{H}_{2} \mathbf{O}$ \\
\hline $118.5 \mathrm{~g} / \mathrm{L}$ & $4.2 \mathrm{~g} / \mathrm{L}$ & $0.9 \mathrm{~g} / \mathrm{L}$ & $1 \mathrm{~L}$ \\
\hline
\end{tabular}

Table 5. Summary of specimens in durability tests.

\begin{tabular}{|l|l|l|l|l|l|l|}
\hline Exposure time (days) & 30 & 60 & 90 & 120 & 150 & 180 \\
\hline $\begin{array}{l}\text { No. of specimens with } \\
\text { GFRP immersed in } \mathbf{2 5}^{\circ} \mathrm{C} \\
\text { solution }\end{array}$ & 4 & 4 & 4 & 4 & 4 & 4 \\
\hline $\begin{array}{l}\text { No. of specimens with } \\
\text { GFRP immersed in } \mathbf{6 0}^{\circ} \mathrm{C}\end{array}$ & 4 & 4 & 4 & 4 & 4 & 4 \\
solution
\end{tabular}

Figure 10. provide an overall illustration of the change in ultimate tensile load of durability specimens caused by the alkaline exposure of GFRP connectors. Although exposure in alkaline solution would decrease the strength of GFRP, the ultimate tensile load of the durability specimens was boosted with increase of exposure time of GFRP connectors. The temperature of alkaline solution had no significant influence on the result of ultimate tensile load. This result agreed with the consequence in tensile tests, revealing that the tensile capacity of the specimens was less correlated with the tensile strength of the GFRP. Exposure in alkaline environment would increase the roughness of the GFRP surface, and therefore enhanced the bond between the GFRP connectors and the concrete. Hence, the ultimate tensile load of the durability specimens gained by GFRP connectors immersed in alkaline solution.

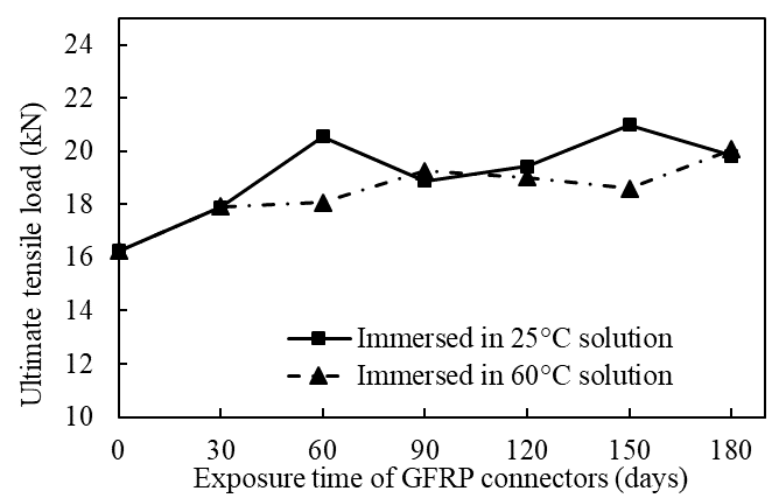

Figure 10. Effect of time of alkaline exposure on ultimate tensile load.

\section{Safety evaluation of precast concrete insulated sandwich panels with GFRP connectors}

According to Chinese code GB 50009-2012 "Load code for the design of building structures" and GB 50011-2010 "Code for seismic design of buildings", the safety evaluation was conducted in accordance with GFRP connectors of precast concrete sandwich exterior wall panels at $100 \mathrm{~m}$ height in $\mathrm{C}$ type landform of southern China. The evaluation model was $3000 \times 2000 \mathrm{~mm}$ wall panel with GFRP connectors arranged at $500 \mathrm{~mm}$ spacing both longitudinally and transversely, as shown in Figure 11. The safety was evaluated for GFRP connectors subjected to combined shear and tension forces, using equation.1 [15].

$$
\frac{P_{s}}{P_{t}}+\frac{V_{s}}{V_{t}} \leq 1
$$

Where $P_{s}$ is the applied service tension load, $P_{t}$ is the service tension load determined by equation. $2, V_{s}$ is the applied service shear load, $V_{t}$ is the service shear load determined by equation. 3 .

$$
P_{t}=\frac{P_{t, u}}{K}
$$

Where $P_{t, u}$ is the ultimate tension capacity, $K$ is the safety coefficient.

$$
V_{t}=\frac{V_{t, u}}{K}
$$

Where $V_{t, u}$ is the ultimate shear capacity, $K$ is the safety coefficient. 


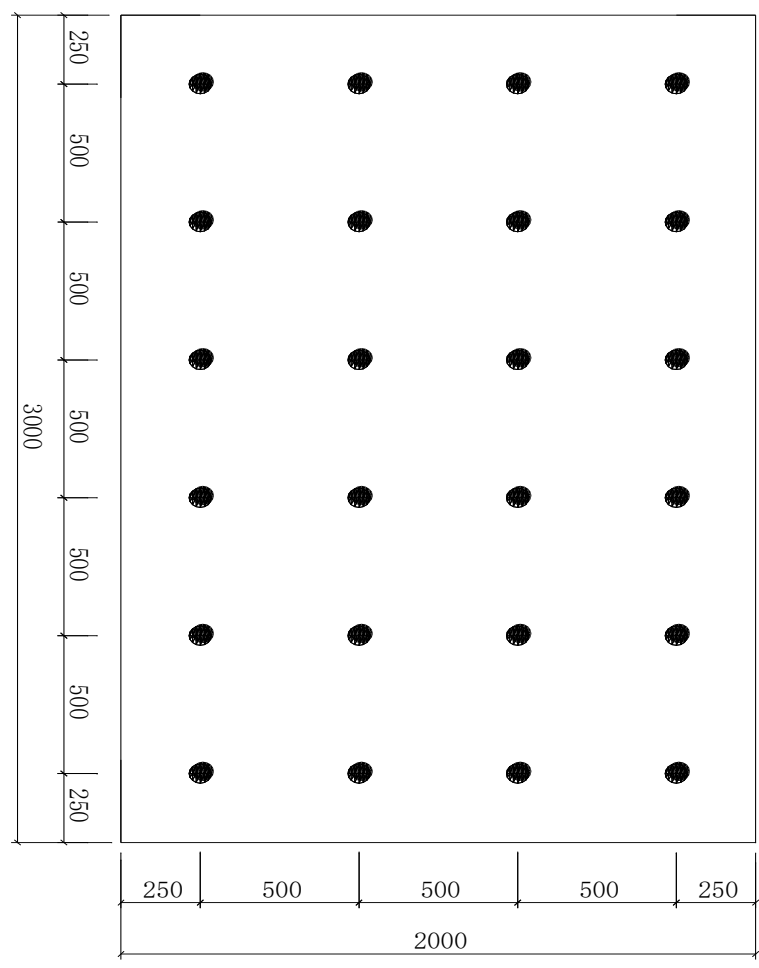

Figure 11. Arrangement of GFRP connectors in sandwich wall (unit:

$\mathrm{mm})$.

Safety evaluation of the precast concrete sandwich panel was conducted under three different design situations, as summarized in Table 6. The result proved that the model of precast concrete sandwich panels with GFRP connectors had adequate safety in all three design situations.

Table 6. Safety evaluation under three different design situations.

\begin{tabular}{|c|c|c|c|c|c|}
\hline Design Situations & $\begin{array}{l}P_{s} \\
(\mathrm{kN} \\
)\end{array}$ & $\begin{array}{l}P_{t} \\
(\mathrm{kN} \\
)\end{array}$ & $\begin{array}{l}V_{s} \\
(\mathrm{kN} \\
)\end{array}$ & $\begin{array}{l}V_{t} \\
(\mathrm{kN} \\
)\end{array}$ & $\frac{P_{s}}{P_{t}}+\frac{V_{s}}{V_{t}}$ \\
\hline Permanent load & 0.36 & \multirow{3}{*}{3.29} & 0.37 & \multirow{3}{*}{3.51} & 0.215 \\
\hline Seismic load & 0.22 & & 0.39 & & 0.178 \\
\hline $\begin{array}{l}\text { Demolding-hoistin } \\
\mathrm{g}\end{array}$ & 0.56 & & 0.56 & & 0.33 \\
\hline
\end{tabular}

\section{Concluding remarks}

This study focused on experimental research on structural performance of precast concrete insulated sandwich panels with cruciform cross section GFRP connectors. Tensile and shear specimens of concrete wythes and XPS insulation with GFRP connectors were fabricated and tested. Durability of sandwich panels was evaluated by testing tensile specimens with GFRP connectors, which were exposed in alkaline solution before placed in the specimens. Safety evaluation of precast concrete sandwich panels with GFRP connectors was conducted based on the results from tensile and shear tests.

According to the results from tensile tests, the failure types of the concrete sandwich specimens with GFRP connectors were concrete splitting or concrete partial cone failure. No significant damage was observed on the GFRP connectors. The average ultimate tension load of the specimens with single GFRP connector was $13.14 \mathrm{kN}$.

The failure type of the shear specimens was rupture of the GFRP connectors. The average ultimate shear load for single GFRP connector was $14.83 \mathrm{kN}$, while the average displacement between the top and bottom concrete wythes was $18.44 \mathrm{~mm}$, correspondingly.

The ultimate load of tensile specimens with GFRP connectors exposed in alkaline environment before fabrication was not compromised by the aging of GFRP. On the contrary, the ultimate load of the specimens gained with the increase of immersion time of GFRP connectors in alkaline solution.

Based on the safety evaluation, precast concrete insulated sandwich panels with GFRP connectors subjected to combined shear and tension load had sufficient safety in different design situations, including permanent load deign, seismic design and demolding-hoisting deign.

Future work may focus on further analysis of mechanism that how specimens with GFRP connectors failed under tension or shear loads. Meanwhile, characteristics could be conducted to investigate how exposure in alkaline solution changing the microstructure of the GFRP connectors surface, and thus influencing the ultimate strength of tensile specimens.

\section{Acknowledgement}

This research was supported by the National Key Research and Development Program of China (2016YFC0701800).

\section{References}

1. W. W. Holmes, D. Kusolthamarat, and M. K. Tadros, PCI Journal 50, 16 (2005)

2. Edward D. Losch, Patrick W. Hynes, Ray Andrews Jr, Ryan Browning, Paul Cardone, Ravi Devalapura, and Rex Donahey, PCI Journal 56, 131 (2011)

3. PCI Industry Handbook Committee, Precast/Prestressed Concrete Institute. PCI Design Handbook: Precast and Prestressed Concrete, 7th Edition (Precast/Prestressed Concrete Institute, 2010)

4. D. Tomlinson and A. Fam, ACI Structural Journal 111, 595 (2014) 
5. S.-J. Jang, H.-R. Kim, Y.-C. You, and H.-D. Yun, Journal of the Architectural Institute of Korea Structure \& Construction 30, 3 (2014)

6. J. Kim and Y.-C. You, Materials 8, 899 (2015)

7. I. Choi, J. Kim, and Y.-C. You, Composites Part B: Engineering 96, 7 (2016)

8. A. Fam and T. Sharaf, Composite Structures 92, 2927 (2010)

9. C. P. Pantelides, R. Surapaneni, and L. D. Reaveley, Journal of Composites for Construction 12, 570 (2008)

10. Y. Lei, X. Ye, Z. Sun, Q. Jiang, H. Li, H. Zhu, L. Wang, and Z. Hao, Industrial Construction 47, 46 (2017)
11. V. Hlavička and É. Lublóy, Construction and Building Materials 171, 588 (2018)

12. Achillides Zenon and Pilakoutas Kypros, Journal of Composites for Construction 8, 173 (2004)

13. H. A. Toutanji and W. Gómez, Cement and Concrete Composites 19, 351 (1997)

14. ACI Commitee 440, Guide Test Methods for Fiber-Reinforced Polymers (FRPS) for Reinforcing or Strengthening Concrete Structures (American Concrete Institute, 2012)

15. ICC Evaluation Service, Inc., Fiber-Reinforced Polymer Composite or Unreinforced Polymer Connectors Anchored in Concrete (2017) 